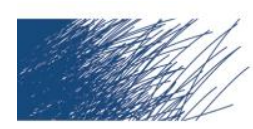

\title{
$\underline{\underline{\text { IIIII }}}$ \\ UNIVERSITEIT GENT
}

biblio.ugent.be

The UGent Institutional Repository is the electronic archiving and dissemination platform for all UGent research publications. Ghent University has implemented a mandate stipulating that all academic publications of UGent researchers should be deposited and archived in this repository. Except for items where current copyright restrictions apply, these papers are available in Open Access.

This item is the archived peer-reviewed author-version of:

Title: Liposomes loaded with quantum dots for ultrasensitive on-site determination of aflatoxin M1 in milk products

Authors: Beloglazova N., Shmelin P., Goryacheva I., De Saeger S.

In: Analytical and Bioanalytical Chemistry, 405(24), 7795-7802, 2013

To refer to or to cite this work, please use the citation to the published version:

Beloglazova N., Shmelin P., Goryacheva I., De Saeger S. (2013). Liposomes loaded with quantum dots for ultrasensitive on-site determination of aflatoxin M1 in milk products. Analytical and Bioanalytical Chemistry, 405(24), 7795-7802. DOI 10.1007/s00216-013-7096-6 


\title{
Liposomes loaded with quantum dots for ultrasensitive on-site determination of aflatoxin M1 in milk products
}

Beloglazova N.V. ${ }^{1}$, Shmelin P.S. ${ }^{2}$, Goryacheva I.Yu. ${ }^{3}$, De Saeger S. ${ }^{1}$

${ }^{1}$ Ghent University, Faculty of Pharmaceutical Sciences, Laboratory of Food Analysis, Harelbekestraat 72, 9000 Ghent, Belgium

2 OJSC CSRIT Technomash, "Neuronet" Department, I. Franko str. 4, 121108 Moscow, Russia

${ }^{3}$ Saratov State University, Chemistry Institute, Department of General and Inorganic Chemistry, Astrakhanskaya 83, 410012 Saratov, Russia

Corresponding author. Tel.: +32 9 2648127; fax: +32 92648199

E-mail address: Natalia.Beloglazova@ugent.be, beloglazovanv@gmail.com (N.V. Beloglazova)

\begin{abstract}
A quantitative fluorescence labeled immunosorbent assay (FLISA) and qualitative onsite column tests were developed for the determination of aflatoxin M1 (AfM1) in milk products. The use of quantum dots (QD) loaded liposomes as a label significantly increased the assay sensitivity by encapsulating multiple QD in a single liposome and, therefore, amplifying the analytical signal.

Two different techniques were compared to obtain aflatoxin-protein conjugates, used for further coupling with the liposomes. The influence of non-specific interactions of the obtained liposomes-labeled conjugates with the surface of microtiter plates and column cartridges was evaluated and discussed. The limit of detection for FLISA was $0.014 \mu \mathrm{g} \mathrm{kg}^{-1}$. For qualitative on-site tests the cut-off was set at $0.05 \mu \mathrm{g} \mathrm{kg}^{-1}$ taking into account the EU maximum level for aflatoxin M1 in raw milk, heat-treated milk and milk for the manufacture of milk based product. The direct addition of labeled conjugate in the milk samples resulted in an additional decrease of analysis time.

An intra-laboratory validation was performed with sterilized milk and cream samples artificially spiked with AfM1 at concentrations less, equal and more than the cut-off level. It was shown that milk products could be analyzed without any sample preparation, just diluted
\end{abstract}


with the buffer. The rates for false positive and false negative results were below $5 \%(2.6 \%$ and $3.3 \%$, respectively).

Keywords: Liposomes; quantum dots; immunoassay; on-site method; fluorescent labeled immunoassay; aflatoxin M1.

\section{Introduction}

Concern about food safety requires the development of rapid and sensitive on-site tests suitable for non-laboratory application. This is especially important for perishable goods, as their short lifetime demands no-delay screening.

One of the contaminants possibly present in food in very low concentrations is aflatoxin M1 (AfM1). Aflatoxins are highly toxic secondary metabolites of Aspergillus species. AfM1, the major metabolite of aflatoxin B1 (AfB1), generated by its hydroxylation in mammals and subsequently secreted in milk of lactating cows, is one of the most dangerous pollutants of milk and milk products. Both AfB1 and AfM1 are characterized with carcinogenic and hepatotoxic activity, so AfM1 has been classified by the International Agency for Research on Cancer (IARC) among other naturally occurring aflatoxins as possibly carcinogenic to humans (Group 2B carcinogen) [1]. AfM1 is relatively stable during milk storage and thermal processing, as well as during production of various dairy products [2]. It makes AfM1 very dangerous for human health. The maximum limit (ML) of AfM1 in

milk established by the US Food and Drug Administration (FDA) is $0.5 \mathrm{ng} \mathrm{mL} \mathrm{m}^{-1}$ [3]. This value for AfM1 in raw milk, heat-treated milk and milk for the manufacture of milk based products according to the European Commission Regulation was set at $0.05 \mu \mathrm{g} \mathrm{kg}^{-1}$ [4].

There are a lot of published data, devoted to the contamination of milk and milk products with AfM1. For example Alborzi et al. [5] described 100\% contamination of analyzed Iranian milk samples with AfM1, Rastogi et al. [6] found this mycotoxin in 87.3\% of tested Indian milk products. Unusan et al. [7] mentioned that the level of AfM1 was above the EU maximum limit in $47 \%$ of analyzed milk samples. Very recently AfB 1 contaminated feed was available on the EU market and fed to lactating cows [8]. Therefore, the problem of AfM1 occurrence in milk deserves a lot of scientific attention and need both laboratory and on-site methods development.

A high performance liquid chromatography with fluorimetric detection coupled with a clean-up treatment by immunoaffinity columns (IC) is the reference method used for the determination of aflatoxins in milk [9]. But a great variety of rapid techniques for AfM1 
detection in milk were published [10]. Most of them were immunochemical tests based on highly specific antigen-antibody interactions. All published immunochemical techniques can be divided in instrumental methods and non-instrumental tests. Enzyme-linked immunosorbent assay (ELISA) [9,11-12], ultrasensitive chemiluminescent enzyme immunoassay [13], flow-injection immunoassay with amperometric detection [14] and different kinds of sensors [15-16] were described. ELISA was even included in ISO guidelines [17] and used for legal purposes (but it requires confirmation by a reference technique). These techniques are characterized with good analytical performances, but they are not suitable for on-site application.

One of the most popular on-site formats applied for AfM1 determination is lateralflow immunoassay (LFIA). LFIA allows the determination of AfM1 with a visual detection limit of $0.3 \mathrm{ng} \mathrm{mL}^{-1}[18]$ and $1 \mathrm{ng} \mathrm{mL}^{-1}$ [11]. Several commercially available LFIA for AfM1 determination in milk are appropriate for qualitative and semi-quantitative detection. However, LFIA often cannot reach the expected sensitivity, according to the established EU ML (limit of detection (LOD) of the R-Biopharm commercial test is $4 \mu \mathrm{g} \mathrm{kg}^{-1}$, LOD of the test produced by Charm Science inc is $0.5 \mu \mathrm{g} \mathrm{kg}^{-1}$, LOD of the test developed by Creative Diagnostics is $0.3 \mu \mathrm{g} \mathrm{kg}^{-1}$ ). To achieve this value some preliminary sample pretreatment is required (the tests from Romer Labs (LOD of $0.047 \mu \mathrm{g} \mathrm{kg}^{-1}$ ) or from Unisensor (LOD of $\left.0.050 \mu \mathrm{g} \mathrm{kg}^{-1}\right)$ ). This can be explained by the impossibility of LFIA to concentrate the target analyte.

A gel-based column immunoassay allows the combination of purification, concentration and sensitive enzyme-based detection in one set-up. Goryacheva et al. [19] reached a cut-off level for AfM1 of $0.04 \mu \mathrm{g} \mathrm{kg}^{-1}$ because $10 \mathrm{~mL}$ of milk could be passed through the immunochemical column. The large volume allowed to pre-concentrate the analyte and to reach high sensitivity, but on the other hand, it gave rise to high matrix interference and needed a centrifugation step for milk defatting.

The most popular labels for immunoassays are enzymes. They provide high sensitivity, but also could be one of the main reasons of false results due to the susceptibility of enzymes to matrix constituents. Besides, additional analysis steps such as washing and application of chromogenic substrate are necessary. Moreover, the enzymatic reaction is timedependent, and a strict compliance with the described assay protocol is important.

Meanwhile, different kinds of particulate and nanosized labels were used for immunoassays e.g., colloidal gold, colloidal carbon, "colloidal dyes", colloidal selenium, 
magnetic nanoparticles, lanthanides, dye entrapped polysterene, liposomes or latex etc [2022]. Each of them has its own strengths and weaknesses.

Quantum dots (QD) play now a significant role in biotechnological and bioanalytical research, due to their unique spectral properties such as intensive fluorescence, high photostability, tunable emission spectra, high-quantum yield and low photobleaching [23]. But transfer of water-insoluble QD into aqueous media usually results in decrease of luminescence yield [24]. However, they can be transferred into aqueous media after loading into liposomes with keeping their spectral characteristics [25].

Liposomes are spherical lipid vesicles. The lipid molecules consist of hydrophilic and hydrophobic groups, so in aqueous solutions they semi-organize to increase the solubility. Due to their extensive internal volume liposomes can carry not one, but a high number of markers. Therefore liposomes were applied in immunoassay [26-28].

The goal of this investigation was the development of a novel ultrasensitive immunochemical on-site test for AfM1 determination in milk based on luminescent determination of the analytical signal. QD-loaded liposomes were synthesized and used as label.

\section{Experimental section}

\section{Reagents and materials}

Lipoid S75 was purchased from Lipoid GMBH (Ludwigshafen, Germany). Nhydroxysuccinimide (NHS), 3-(2-Pyridyldithio)propionic acid N-hydroxysuccinimide ester (SPDP), ethyl-3-(3-dimethylaminopropyl)carbodiimide (EDC), dithiothreitol (DTT), O-(carboxymethyl)hydroxylamine hemihydrochloride (CMO), albumin from chicken egg white (OVA), bovine serum albumin (BSA), $N, N$-dimethylformamide (DMFA), Sephadex G75, 2-(N-Morpholino)ethanesulfonic acid (MES), EDTA tetrapotassium salt were purchased from Sigma-Aldrich (Bornem, Belgium). AfM1 was supplied by Fermentek (Jerusalem, Israel). Imject Cationized BSA (cBSA Immune Modulator) and protein concentrators (9K, 20 $\mathrm{mL}$ ) were purchased from Thermo Scientific (Rockford, USA). Anti-AFB1 (monoclonal) was obtained from Soft Flow Hungary Ltd (Pecs, Hungary). It was characterized with $79 \%$ crossreaction with aflatoxin $\mathrm{M} 1,33 \%$ with aflatoxin $\mathrm{M} 2,76 \%$ with $\mathrm{AfB} 2,55 \%$ with $\mathrm{AfG} 1,6 \%$ with AfG2 and none at all with AfB2a and AfG2a [29]. CNBr-activated sepharose 4B was purchased from GE Healthcare Bio-Sciences AB (Uppsala, Sweden). Plastic tubes (Bond Elut catridges, $1 \mathrm{~mL}$ ) and polyethylene frits (1/4 in. diameter) were supplied by Varian Belgium 
NV/SA (Sint-Katelijne-Waver, Belgium). Microtiter plates (96 flat-bottom wells with high binding capacity; black Maxisorp) were purchased from Nunc A/S (Roskilde, Denmark). Certified reference material (CRM) - whole milk powder with an AfM1 certified value at $111 \pm 0.018 \mu \mathrm{g} \mathrm{kg}^{-1}$ and $0.44 \pm 0.06 \mu \mathrm{g} \mathrm{kg}^{-1}$ - was supplied by the Institute for Reference Materials and Measurements (European Commission, Joint Research Centre, Geel, Belgium). Milk products (milk, cream) were bought in Belgian supermarkets.

Size distribution of the liposomes was measured by using the Zetasizer Nano ZS (Malvern, England). All measurements were carried out at $25^{\circ} \mathrm{C}$.

Water-insoluble CdSe/3CdS/2ZnS core/shell/shell QD were synthesized by Elena S. Speranskaya and Valentina V. Goftman (Saratov State University, Saratov, Russia). $\lambda_{\mathrm{ex}}=380$ $\mathrm{nm}, \lambda_{\mathrm{em}}=590 \mathrm{~nm}$.

\section{Synthesis of AfB1-cBSA and AfM1-cBSA}

For aflatoxin-cBSA synthesis an adapted technique described by Zhou et al. was applied. [30]. The mycotoxin $(\sim 1 \mu \mathrm{mol})$ was dissolved in $1 \mathrm{~mL}$ of $0.1 \mathrm{M}$ MES buffer $(\mathrm{pH}$ 4.8, containing $100 \mu \mathrm{L}$ of DMFA) and added dropwise to cBSA solution $(0.025 \mu \mathrm{mol})$. Formaldehyde $(150 \mu \mathrm{L})$ was added. The mixture was gently stirred for $24 \mathrm{~h}$ at $37{ }^{\circ} \mathrm{C}$. For removal of unbound low-molecular weight substances, protein concentrator tubes $20 \mathrm{~mL} / 9 \mathrm{~K}$ were used. Concentrations of the obtained conjugates were determined spectrophotometrically. AfB1-cBSA $\left(0.7 \mathrm{mg} \mathrm{mL}^{-1}\right)$ and AfM1-cBSA $\left(0.6 \mathrm{mg} \mathrm{mL}^{-1}\right)$ were kept at $-18{ }^{\circ} \mathrm{C}$.

Synthesis of AfB1-OVA and AfM1-OVA

Carboxymethoxylamine (CMO) was used to include carboxyl groups in AfB1 and AfM1. The AfB1-ovalbumin (AfB1-OVA) and AfM1-ovalbumin (AfM1-OVA) conjugates were synthesized according to the standard technique of $\mathrm{N}$-hydroxysuccinimide/ $\mathrm{N}, \mathrm{N}^{\prime}-$ dicyclohexylcarbodiimide activation of hapten's COOH-group. NHS $(\sim 2 \mu \mathrm{mol})$ and EDC $(\sim 2$ $\mu \mathrm{mol})$ in DMFA were added dropwise to the obtained derivatised mycotoxins solution $(\sim 0.2$ $\mu \mathrm{mol}$ ), and the reaction was kept for $2.5 \mathrm{~h}$ at RT under constant magnetic stirring. The activated derivate was mixed with the previously cooled OVA solution ( 4 nmol) and kept for $2 \mathrm{~h}$ at RT under stirring followed by overnight incubation at $4{ }^{\circ} \mathrm{C}$. 
The conjugates were dialyzed ( 3 days against $\mathrm{PBS}$, at $4{ }^{\circ} \mathrm{C}$, constant stirring). Concentrations of AfB1-OVA $\left(0.3 \mathrm{mg} \mathrm{mL}^{-1}\right)$ and AfM1-OVA $\left(0.3 \mathrm{mg} \mathrm{mL}^{-1}\right)$ were determined spectrophotometrically. The obtained conjugates were kept at $-18{ }^{\circ} \mathrm{C}$.

\section{Preparation of QDs-loaded liposomes ( $L Q D)$}

The preparation of LQD was based on the technique, described by Bangham et al. [31]. Lipoid S75 $(94 \mu \mathrm{mol})$ and the water insoluble QDs $(1 \mathrm{nmol})$ were dissolved in $1 \mathrm{~mL}$ of chloroform. The organic solvent was removed by rotary evaporation at $45{ }^{\circ} \mathrm{C}$. Then, $6 \mathrm{~mL}$ of PBS were added to the dried lipids and the mixture was vigorously stirred in a water bath at $45^{\circ} \mathrm{C}$ for $30 \mathrm{~min}$. The desired particle size was obtained by sonication $(5 \mathrm{~min})$. The liposomes suspension was centrifuged at $20000 \mathrm{~g}$ for $15 \mathrm{~min}\left(\mathrm{RT}^{\circ} \mathrm{C}\right)$ and the supernatant was removed. The pellet was re-dissolved in PBS and used for further experiments. The obtained LQD solution was stored at $4{ }^{\circ} \mathrm{C}$. Prepared LQD were stored at $4{ }^{\circ} \mathrm{C}$ and proved stable for at least 1 month.

\section{Synthesis of liposome-labeled conjugate}

SPDP (1.8 mg in $300 \mu \mathrm{L}$ of ethanol) was added dropwise to the analyte-protein conjugates (AfM1-OVA, AfB1-OVA, AfB1-cBSA, AfM1-cBSA; $2 \mu \mathrm{mol}$ of conjugate in 2 $\mathrm{mL}$ of $0.1 \mathrm{M}$ sodium phosphate buffer, $\mathrm{pH}$ 7.5). The reaction mixtures were stirred during 30 min at RT, and excess of the crosslinker was removed by application of the protein concentrator tubes $(20 \mathrm{~mL} / 9 \mathrm{~K})$. The residues were reconstituted in sodium acetate buffer (pH 4.5). For pyridine-2-thione release DTT $(0.8 \mathrm{mg}$ in $100 \mu \mathrm{L}$ of acetate buffer) was added dropwise to the SPDP-modified protein conjugates and the reaction continued during $30 \mathrm{~min}$ under constant stirring at RT. Excess of DTT was removed by the protein concentrator tubes $(20 \mathrm{~mL} / 9 \mathrm{~K})$, and the modified conjugates were reconstituted in $0.05 \mathrm{M}$ sodium phosphate buffer (containing $1 \mathrm{mM}$ EDTA).

For liposomes thiolation $300 \mu \mathrm{L}$ of SPDP $(2.5 \mu \mathrm{mol})$ were mixed with $2 \mathrm{~mL}$ of LQD. The reaction mixture was stirred during $2 \mathrm{~h}$ at RT, and excess of the crosslinker was removed by the protein concentrator tube. The vesicles were suspended in $0.05 \mathrm{M}$ sodium phosphate buffer, containing $1 \mathrm{mM}$ EDTA.

Modified LQD $(1.7 \mathrm{~mL})$ was added dropwise to the thiolated analyte-protein conjugates. Reactions were performed under constant stirring overnight at RT. The modified 
liposomes were separated from excess protein by gel-filtration using Sephadex G-75 and kept at $4{ }^{\circ} \mathrm{C}$. Prepared conjugates were stored at $4{ }^{\circ} \mathrm{C}$ and proved stable for at least 1 month.

\section{Microtiter plate fluorescence-labeled immunosorbent assay (FLISA)}

The 96-well opaque black microtiter plates were coated with anti-AfB1 antibody (dilution 1/50 000, $100 \mu \mathrm{L}$ well ${ }^{-1}$ ) in coating buffer (0.05 M sodium carbonate buffer, $\mathrm{pH}$ 9.6, CBS) by an overnight incubation at $4{ }^{\circ} \mathrm{C}$ or for $2 \mathrm{~h}$ at $37{ }^{\circ} \mathrm{C}$. Afterwards, the plates were washed three times with PBS containing $0.05 \%$ (v/v) Tween 20 (PBST) and blocked for $1 \mathrm{~h}$ at $37{ }^{\circ} \mathrm{C}$ with PBS containing $2 \%$ casein (w/v). The plates were later washed two times with PBST. AfM1 standard solution in PBS or diluted milk sample $\left(50 \mu \mathrm{L}^{-1}\right.$ well $\left.^{-1}\right)$ was added simultaneously with the LQD-labeled conjugate (dilution $1 / 50,50 \mu \mathrm{L}$ well ${ }^{-1}$ ). After 1 hourincubation the plates were washed four times with PBST. The content of each well was redissolved in $100 \mu \mathrm{L}$ of PBS. Luminescence was measured using the Envision 2104 Multilabel Plate

Reader

(Waltham

Massachusetts, USA).

The standard FLISA sigmoidal curve was plotted in a semi logarithmic scale: luminescence intensity or relative luminescence intensity (ratio of values of luminescence intensity measured at standard concentrations and zero concentration) against logarithm of analyte concentration. It is described by the Rodbard's function:

$$
\mathrm{y}=(\mathrm{A}-\mathrm{D}) /\left[1+(\mathrm{x} / \mathrm{C})^{\mathrm{b}}\right]+\mathrm{D}
$$

A: maximum luminescence intensity value, D: minimum luminescence intensity value, b: slope of the curve in the $\mathrm{IC}_{50}$ plot, $\mathrm{C}: \mathrm{IC}_{50}$ concentration of analyte. LOD was defined as three times the signal-to-noise ratio.

\section{Gel-based immunoassay (GBI) for on-site detection}

Sepharose 4B gel coupled with the anti-AfB1 antibody $(9 \mu \mathrm{L}$ of antibody for $0.5 \mathrm{~g}$ of Sepharose; coupled gel) and gel with blocked active groups (blocked gel) were prepared according to the standard procedure [32]. Mixture of coupled and blocked gels (200 $\mu \mathrm{L})$ was placed between two polyethylene frits inside an empty 1-mL Bond Elut column. The column was kept at $4{ }^{\circ} \mathrm{C}$ until use. Before analysis, the immunochemical columns were additionally blocked with $1 \%$ glycine (w/v) in $0.1 \mathrm{M}$ hydrocarbonate buffer $(\mathrm{pH} / 8)$.

AfM1 standard solution $(1 \mathrm{~mL})$ or diluted milk sample $(1 \mathrm{~mL})$ was passed through the column. After a washing step with $1 \mathrm{~mL}$ of PBS, $100 \mu \mathrm{L}$ of labeled conjugate (diluted 1/50) 
were added and incubated for 6 min. Afterwards, excess of the conjugate was removed with 1 $\mathrm{mL}$ of PBS. Visual detection was performed immediately after the washing step under a UV lamp (365 nm).

\section{Polyethylene frit-based immunoassay (FBI) for on-site detection}

The frit-based column immunoassay procedure was described in our previous publications $[32,33]$. First, polyethylene frits were degassed in ethanol by ultrasonication (15 min). Then they were placed in $1 \mathrm{~mL}$ Bond Elut catridges, and $300 \mu \mathrm{L}$ of ethanol/water (50/50, v/v), $300 \mu \mathrm{L}$ of water and $600 \mu \mathrm{L}$ of carbonate buffer were passed through the columns for further activation. The anti-AfB1 antibody $(200 \mu \mathrm{L}$, diluted 1/30 000 in CBS) was immobilized directly onto the activated polyethylene frits and incubated for 20 min at 37 ${ }^{\circ} \mathrm{C}$. Excess of unbound antibody was removed, and the frits' surface was blocked with PBS containing $3 \%$ casein $\left(500 \mu \mathrm{L}\right.$ per frit, $15 \mathrm{~min}$ incubation, $\left.37^{\circ} \mathrm{C}\right)$. The further procedure was similar as described for the GBI.

In another variant of this on-site test, the labeled conjugate was directly added in the milk sample prior to its analysis. This approach allowed to shorten the analysis procedure. In this case visual detection was realized immediately after the sample addition and washing step. PBS ( $2 \mathrm{~mL})$ was used to remove excess of the unbound conjugate.

\section{Analytical performance of the column tests}

The cut-off level of the column tests was defined as the lowest AfM1 concentration which did not result in appearance of luminescence. Absence of luminescence of the test layer was considered as a positive result (analyte concentration at or above the cut-off level), presence of luminescence, independent on its brightness, as a negative sample (analyte concentration below the cut-off level). Samples with AfM1 concentrations higher (or lower) than the cut-off level, which resulted in negative results (or positive results) were considered to be false negative (or false positive), respectively.

\section{Sample preparation}

For milk and cream samples preparation, a fivefold dilution with PBS was used. Milk powder was suspended in distilled water and dissolved by stirring. For each milk sample, control portions were prepared at an AfM1 concentration level of $0.05 \mu \mathrm{g} \mathrm{kg}^{-1}$. 


\section{Result and discussion}

\section{Preparation of LQD-labeled conjugates for AfM1 determination}

QD-loaded liposomes were prepared by thin-film evaporation using soybean lecithin derived material (Lipoid S75). This procedure consists in 2 steps: the formation of a phospholipids' thin film and its hydratation for liposomes formation.

In this work $\mathrm{CdSe} / 3 \mathrm{CdS} / 2 \mathrm{ZnS}$ core/shell/shell QDs were used. Uncovered CdSe nanocrystals are characterized with low quantum yield (QY) and they are not photostable [34, 35]. The QY and photostability can be sufficiently improved by growing an inorganic shell of a wider band-gap semiconductor around the CdSe cores [34]. In this work, the SILAR technique was used to cover the CdSe cores with an inorganic $\mathrm{ZnS}$ shell. The initial $\mathrm{CdSe}$ core $(\lambda($ emission $)=524 \mathrm{~nm}$ ) has a QY of $1.5 \%$, while after coating with $\mathrm{CdS}$ and $\mathrm{ZnS}$ layers the QY of QDs was sufficiently increased ( 35\%).

As the molecular structures of AfB1 and AfM1 are similar and the difference is just in one hydroxyl group, it is more than possible that antibodies against AfM1 could be characterized with high cross-reactivity to AfB1, and vice versa, antibodies against AfB1 could be sensitive to AfM1 too. Therefore both AfB1 and AfM1 were used to synthesize labeled conjugates for AfM1 determination. Neither AfB1, nor AfM1 contains active groups suitable for binding with proteins. Therefore, two different conjugation techniques were used to couple aflatoxin molecules with proteins. The first method was based on the synthesis of carboxymethoxylamine derivates of AfM1 and AfB1. The other approach was based on the Mannich reaction of the mycotoxin with cBSA and consisted of imidization of $\mathrm{N}$ hydroxymethyl amine groups of cBSA, enolation of aflatoxin and reaction when electrophilic iminium ionized BSA attacked the $\mathrm{C}$-nucleophilic center of the enolated aflatoxin. Addition of formaldehyde in the reaction mixture was necessary, because it participates in cBSA imidization. The reaction was done in MES buffer $(\mathrm{pH} 4.8)$ since acidic conditions are important for ketone enolization.

The prepared analyte-protein conjugates were used for coupling with QD-loaded liposomes. Lipoid S75 contains 7-10\% (w/w) of phosphatidylethanolamine, which provides active amino-groups on the liposomes' surface and stabilizes the obtained vesicles. Both analyte-protein conjugate and LQD were modified by SPDP, the heterobifunctional crosslinker. Amino groups of LQD could react with SPDP and formed an amide bond. The 2pyridyldithiol end of SPDP participated in the formation of a disulfide linkage with sulfhydryl 
groups of other molecules. Therefore, after activation of the proteins and LQD with SPDP, they reacted and coupled with each other.

\section{Fluorescent labeled immunoassay for AfM1 determination}

Four synthesized conjugates (AfB1-cBSA-LQD, AfM1-cBSA-LQD, AfB1-OVALQD, AfM1-OVA-LQD) were applied for AfM1 determination by FLISA. It was the objective to develop FLISA with a sensitivity close or lower than the maximum limit for AfM1 in milk and milk products, established by the European Commission. The envisaged sensitivity was reached through variation of antibody and labeled conjugate concentrations. The conjugates obtained via CMO-derivatives were characterized by a considerably stronger non-specific interaction with the microtiter plate, than the conjugates based on the binding with cBSA. To level this interaction a high casein concentration was used in the blocking solution (PBS-2\% casein, w/v). It resulted in the suppression of luminescence intensity, and for amplification of the analytical signal the antibody concentration was increased. Thus, the sensitivities of AfM1 determination with AfB1-OVA-LQD ( $\mathrm{IC}_{50}$ was $0.32 \mu \mathrm{g} \mathrm{kg}^{-1}$ ) and AfM1OVA-LQD ( $\mathrm{IC}_{50}$ was $0.31 \mu \mathrm{g} \mathrm{kg}^{-1}$ ) were considerably lower, than the sensitivity of analysis based on AfM1-cBSA-LQD ( $\mathrm{IC}_{50}$ was $0.015 \mu \mathrm{g} \mathrm{kg}^{-1}$ ) and AfB1-cBSA- LQD ( $\mathrm{IC}_{50}$ was 0.014 $\mu \mathrm{g} \mathrm{kg}^{-1}$ ) (Fig. 1). For further experiments AfB1-cBSA-LQD was chosen. The reached LOD $\left(0.0025 \mu \mathrm{g} \mathrm{kg}^{-1}\right)$ allowed analyzing AfM1 in milk products. As the LOD was considerably lower than the EU ML for AfM1 in milk, it allowed to use high dilution of milk samples.

\section{Column tests for AfM1 determination}

As carriers for antibody immobilization CNBr-activated sepharose gel and thin polyethylene frits were used. The targeted cut-off level was based on the EU ML for AfM1 in milk and milk products $\left(0.05 \mu \mathrm{g} \mathrm{kg}^{-1}\right)$. Bearing in mind the sample dilution (1/5 with PBS) the assay sensitivity should be around $0.01 \mu \mathrm{g} \mathrm{kg}^{-1}$. The analytical signal was registered by the naked eye, so the luminescence intensity should be high enough for unambiguous detection. At the same time the assay sensitivity should be high enough to reach the established ML. In the FBI the specific antibody was directly coated onto the frit surface; eight different antibody concentrations were compared (dilutions were from 1/500 to 1/30 000 in CBS). In the GBI, when the antibody was covalently bound with active CNBr-groups of sepharose, various dilutions of coupled gel with blocked gel were checked (from 1/10 to 1/75). Low antibody concentrations in the FBI (dilution higher than 1/30 000) or high gel dilutions in the GBI 
(higher than 1/50) showed a very low intensity of the analytical signal, that could cause false results during the analysis of real samples. As optimal conditions, an antibody dilution of 1/30 000 for FBI and 1/50 gel dilution for GBI were chosen. The optimal AfB1-cBSA-LQD dilution was $1 / 50$.

The optimal time for antibody coating in FBI was 20 min at $37{ }^{\circ} \mathrm{C}$. Further incubation did not lead to an increased analytical signal, but a shorter coating time was not enough. Blocking in FBI was necessary to prevent undesirable physical absorption of the labeled conjugate on the frit's surface. Thus, blocking was done with $3 \%$ casein-PBS (w/v) during 15 $\min$ at $37^{\circ} \mathrm{C}$.

PBS-Tween $20(0.1 \% \mathrm{v} / \mathrm{v})$ was used as washing buffer for conjugate dilution in both FBI and GBI. For additional blocking of the gel in GBI $1 \%$ glycine (w/v) in $0.1 \mathrm{M} \mathrm{NaHCO}_{3}$ buffer ( $\mathrm{pH} 8$ ) was added in the already prepared immunocolumns, incubated during $10 \mathrm{~min}$ at room temperature and passed through. It was done to block unbound $\mathrm{CNBr}$-groups of sepharose.

To decrease the analysis time and simplify the analytical procedure the labeled conjugate was also directly added in the analyzed samples. This approach enabled to completely level the non-specific interaction of AfB1-cBSA-LQD with the polyethylene frit without using additional blocking with casein. It became possible because milk as a multicomponent mixture, which contains different proteins, acted as an additional blocking agent. But, the presence of this protein mixture decreased luminescence of the LQDs-labeled conjugate, so, the concentration of AfB1-cBSA-LQD had to be increased (in this case the optimal dilution of AfB1-cBSA-LQD was 1/40). For washing $5 \mathrm{ml}$ of PBS were used to remove excess of unbound conjugate.

The achieved cut-off value was $0.05 \mu \mathrm{g} \mathrm{kg}^{-1}$ in both formats with a visible and clear contrast in luminescence between positive and negative samples (Fig. 2).

\section{Validation of developed techniques}

FLISA validation was performed with milk and cream samples, artificially spiked with AfM1 at concentrations less, equal and more than the established ML for AfM1 in milk products. As a sample pretreatment a fivefold dilution of milk with PBS was used. LQD are less susceptible for the matrix content, than enzymes, and luminescence is easier to detect by the naked eye. The correlation between added amounts of AfM1 and found concentrations is pointed out in Fig. 3. The obtained graphs demonstrate a good applicability of the developed 
technique for the screening of milk samples. For accuracy control two certified reference materials with $0.111 \pm 0.018 \mu \mathrm{g} \mathrm{kg}^{-1}$ and $0.44 \pm 0.06 \mu \mathrm{g} \mathrm{kg}^{-1}$ of AfM1 were used and $0.093 \mu \mathrm{g}$ $\mathrm{kg}^{-1}$ and $0.452 \mu \mathrm{g} \mathrm{kg}^{-1}$ of AfM1, respectively, were found by FLISA.

The validation of on-site column tests was performed with a sterilized milk sample artificially spiked with AfM1. Standard solutions and artificially spiked milk samples with AfM1 concentrations equal to or more than the cut-off level resulted in no luminescence observation under a UV lamp. Inversely, standard solutions and artificially spiked milk samples with AfM1 concentrations less than $0.05 \mu \mathrm{g} \mathrm{kg}^{-1}$ resulted in bright luminescence under UV light (Fig.4).

Performance parameters were calculated based on the summarized data of repeated experiments. The rates for false positive and false negative results were below 5\% $(2.6 \%$ and $3.3 \%$, respectively) and the specificity and sensitivity rates were $>95 \%$, so according to Commission Decision 2002/657/EC [35].

\section{Conclusion}

QD-loaded liposomes were used to detect an analytical signal in two different formats of immunosorbent assay: FLISA and non-instrumental qualitative column tests (gel-based and frit-based formats). Two different approaches for AfM1-protein conjugate preparation were evaluated and use of cBSA was found optimal. Direct addition of labeled conjugate in the analyzed samples was successfully applied and thereby the analysis procedure could be shortened and simplified. The cut-off values were aimed at the maximum level for AfM1 in milk products established by the European Commission $\left(0.05 \mu \mathrm{g} \mathrm{kg}^{-1}\right)$. Application of the QD-loaded liposomes allowed to reach the $\mathrm{IC}_{50}$ value in FLISA of $0.014 \mu \mathrm{g} \mathrm{kg}^{-1}$ and the cutoff for both on-site formats of $0.05 \mu \mathrm{g} \mathrm{kg}$. The developed ultra sensitive systems for aflatoxin M1 determination were tested and validated for rapid screening of milk products.

\section{Acknowledgment}

This research was financially supported by the Belgian Federal Science Policy Office (BELSPO) in order to promote the S\&T cooperation with China (contract No BL/02/C58), the Special Research Fund (BOF), Ghent University (01SB2510) and the Russian Foundation of Basic Research (RFBR, project 12-03-91167). We gratefully acknowledge Prof. Tom Coenye (Ghent University) for making available the Envision 2104 Multilabel Plate Reader, Prof S. 
De Smedt for giving the opportunity to perform the experiments in his laboratory and Dr. Bart Lucas for his appreciable advice. 


\section{References:}

1. International Agency for Research on Cancer (2002) Monograph on the Evaluation of carcinogenic risks in humans: Some Traditional Herbal Medicines, Some Mycotoxins, Naphthalene and Styrene; Vol. 82, pp. 171-274 IARC, Lyon, France

2. Iha MH, Barbosa CB; Okada IA, Trucksess MW (2013) Food Control 29(1):1-6

3. FAO (Food and Agriculture Organization of the United Nations) (2004). Worldwide Regulations for Mycotoxins in Food and Feed in 2003. Food and Nutrition Paper, 81. Rome: FAO

4. European Commission Regulation (2006) No 1881/2006/EC of 19 December 2006, setting maximum levels for certain contaminants in foodstuffs. Official Journal of European Communities, L364, 5-24

5. Alborzi S, Pourabbas B, Rashidi M, Astaneh B (2006) Food Control 17:582-584

6. Rastogi S, Dwivedi PD, Khanna SK, Das M (2004) Food Control 15:287-290

7. Unusan N (2006) Food Chem Toxicol 44:1897-1900

8. RASFF Notifications (2013) Weeks 5-8

9. Radoi A, Targa M, Prieto-Simon B, Marty JL (2008) Talanta 77:138-143

10. Shephard GS, Berthiller F, Burdaspal PA, Crews C, Jonker MA, Krska R, MacDonald S, Malone RJ, Maragos C, Sabino M, Solfrizzo M, Van Egmond HP, Whitaker TB (2012) World Mycotoxin J 5(1):3-30

11. Wang JJ, Liu BH, Hsu YT, Yu FY (2011) Food Control 22:964-969

12. Duarte SC, Almeida AM, Teixeira AS, Pereira AL, Falcao AC, Pena A, Lino CM (2013) 30(2): 41-417

13. Magliulo M, Mirasoli M, Simoni P, Lelli R, Portanti O, Roda A (2005) J Agric Food Chem 53:3300-3305

14. Badea M, Micheli L, Messia MC, Candigliota T, Marconi E, Mottram T, VelascoGarcia M, Mosconea D, Palleschi G (2004) Anal. Chim. Acta 520:141-148

15. Larou E, Yiakoumettis I, Kaltsas G, Petropoulos A, Skandamis P, Kintzios S (2013) Food Control 29:208-212.

16. Micheli L, Grecco R, Badea M, Moscone D, Palleschi G (2005) Biosens Bioelectron 21:588-596

17. ISO (2002) Geneva, Switzerland: International Standards Organisation. Standard 14675

18. Zhang DH, Li PW, Zhang Q, Yang Y, Zhang W, Guan D, Ding XX (2012) Anal Methods 4:3307-3313. 
19. Goryacheva IYu, Karagusheva MA, Van Peteghem C, Sibanda L, De Saeger S (2009) Food Control 20:802-806

20. Posthuma-Trumpie GA, Korf J, Van Amerongen A (2009) Anal Bioanal Chem 393:569-582

21. Goryacheva IYu, Lenain P, De Saeger S (2013) Nanosized labels for rapid immunotests. TrAC. Doi: $\underline{10.1016 / j . t r a c .2013 .01 .013}$

22. Maragos C, Busman M (2010) Food Addit Contam: Part A 27(5):688-700

23. Park JJ, De Paoli Lacerda SH, Stanley SK, Vogel BM, Kim S, Douglas JF, Raghavan D, Karim A (2009) Langmuir 25: 443-450

24. Gill R, Zayats M, Willner I (2008) Angew. Chem. Int. Ed. 47:7602-7625

25. Dubertret B, Skourides P, Norris D.J, Noireaux V, Brivanlou A.H, Libchaber A (2002) Science 298:1759-1762

26. Ho JAA, Wauchope RD (2002) Anal Chem 74:1493-1496

27. Edwards KA, Wang Y, Baeumner AJ (2010) Anal Bioanal Chem 398(6):2645-2654

28. Rongen HAH, Bult A, Van Bennekom WP (1997) J Immunol Methods 204:105-133

29. Goryacheva IY, De Saeger S, Delmulle B, Lobeau M, Eremin SA, Barna-Vetro I, Van Peteghem C (2007) Anal Chim Acta 590:118-124

30. Zhou Y, Wu J, Yu W, Xu Y, Wang P, Xie B, Chen F (2007) J Immunol Methods 328:79-88

31. Bangham AD, Standish MM, Watkins JC (1965) J Mol Biol 13:238-252

32. Beloglazova NV, Speranskaya ES, De Saeger S, Hens Z, Abé S, Goryacheva IY (2012) Anal Bioanal Chem 403(10):3013-3024

33. Beloglazova NV, Goryacheva IY, De Saeger S, Scippo ML, Niessner R, Knopp D (2011) Talanta 85:151-156

34. Reiss P, Protière M, Liang L (2009) Small 5(2):154-168

35. Lim SJ, Chon B, Joo T, Shin SK (2008) J Phys Chem C 112 (6):1744-1747

36. EC (2006) Commission Regulation 401/2006 of 23 February 2006 laying down the methods of sampling and analysis for the official control of the levels of mycotoxins in foodstuffs. Off. J. Eur. Union L 70/12 


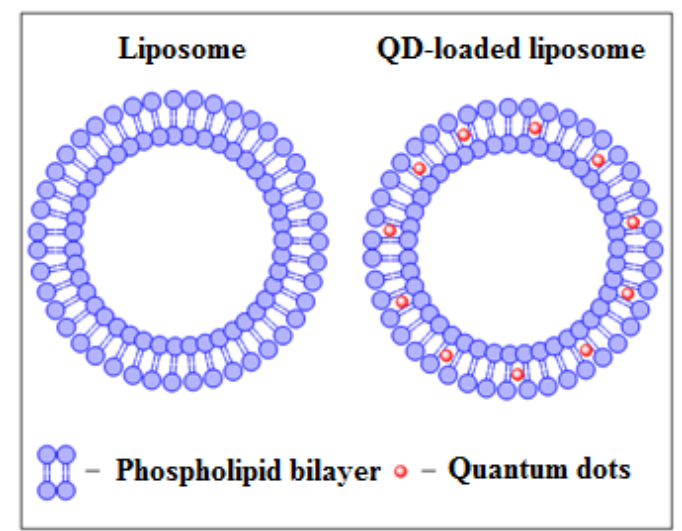

Grafic abstract 


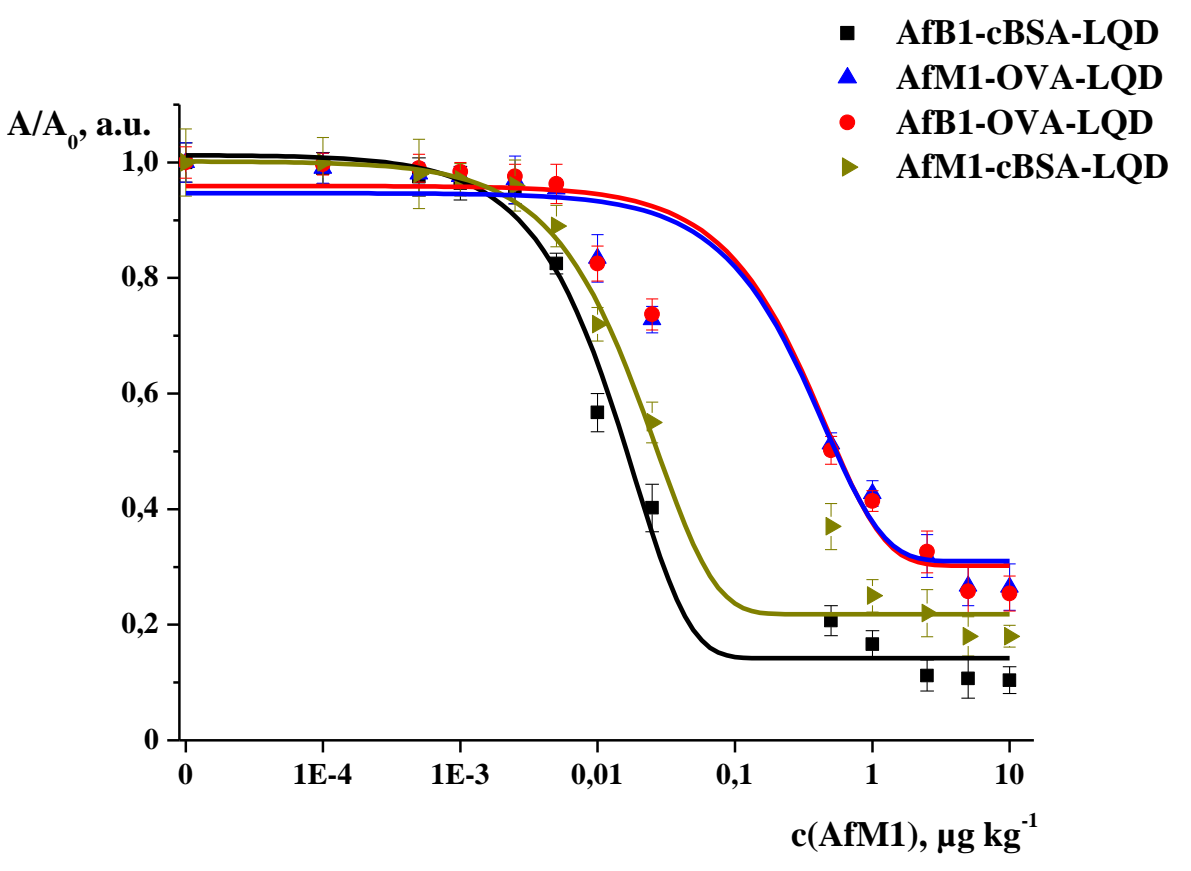

\begin{tabular}{|c|c|c|c|c|}
\hline & $\begin{array}{c}\text { AfB1-cBSA- } \\
\text { LQD }\end{array}$ & $\begin{array}{c}\text { AfM1-cBSA- } \\
\text { LQD }\end{array}$ & $\begin{array}{c}\text { AfB1-OVA- } \\
\text { LQD }\end{array}$ & $\begin{array}{c}\text { AfM1-OVA- } \\
\text { LQD }\end{array}$ \\
\hline LOD, $\mu \mathrm{g} \mathrm{kg}^{-1}$ & $2.5 \times 10^{-3}$ & $3 \times 10^{-3}$ & $24 \times 10^{-3}$ & $15 \times 10^{-3}$ \\
\hline IC $_{\mathbf{5 0}}, \mu \mathrm{g} \mathrm{kg}^{-1}$ & $14 \pm 2 \times 10^{-3}$ & $15 \pm 3 \times 10^{-3}$ & $323 \pm 14 \times 10^{-3}$ & $305 \pm 9 \times 10^{-3}$ \\
\hline Linear range, $\mu \mathrm{g} \mathrm{kg}^{-1}$ & $5-32 \times 10^{-3}$ & $6-32 \times 10^{-3}$ & $83-859 \times 10^{-3}$ & $71-820 \times 10^{-3}$ \\
\hline
\end{tabular}

Fig. 1 FLISA calibration curves for aflatoxin M1 determination in standard solutions with different conjugates: AfB1-cBSA-LQD, AfM1-OVA-LQD, AfB1-OVA-LQD, AfM1-cBSALQD ( $\mathrm{n}=5) . \lambda_{\mathrm{ex}}=380 \mathrm{~nm}, \lambda_{\mathrm{em}}=590 \mathrm{~nm}$. Analytical parameters are presented in the table (data indicate averages of fivefold determinations) 
A.

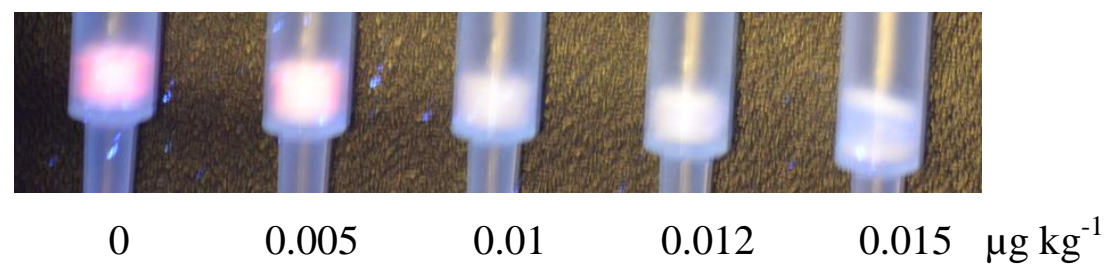

B.

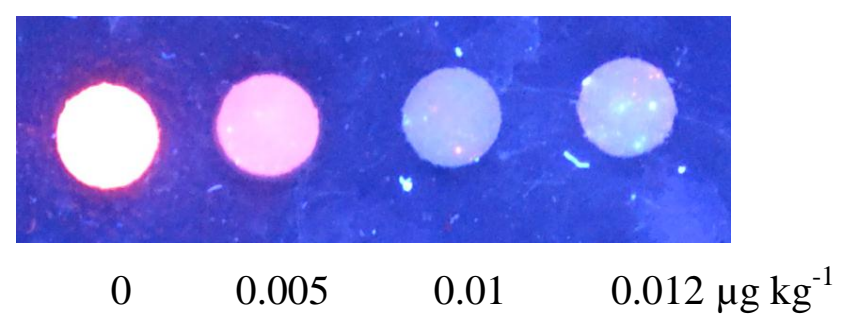

Fig. 2 Aflatoxin M1 detection by gel-based (A) and frit-based (B) column immunoassay. The cut-off for both formats was $0.01 \mu \mathrm{g} \mathrm{kg}^{-1}$ (for fivefold diluted milk samples) 
A.
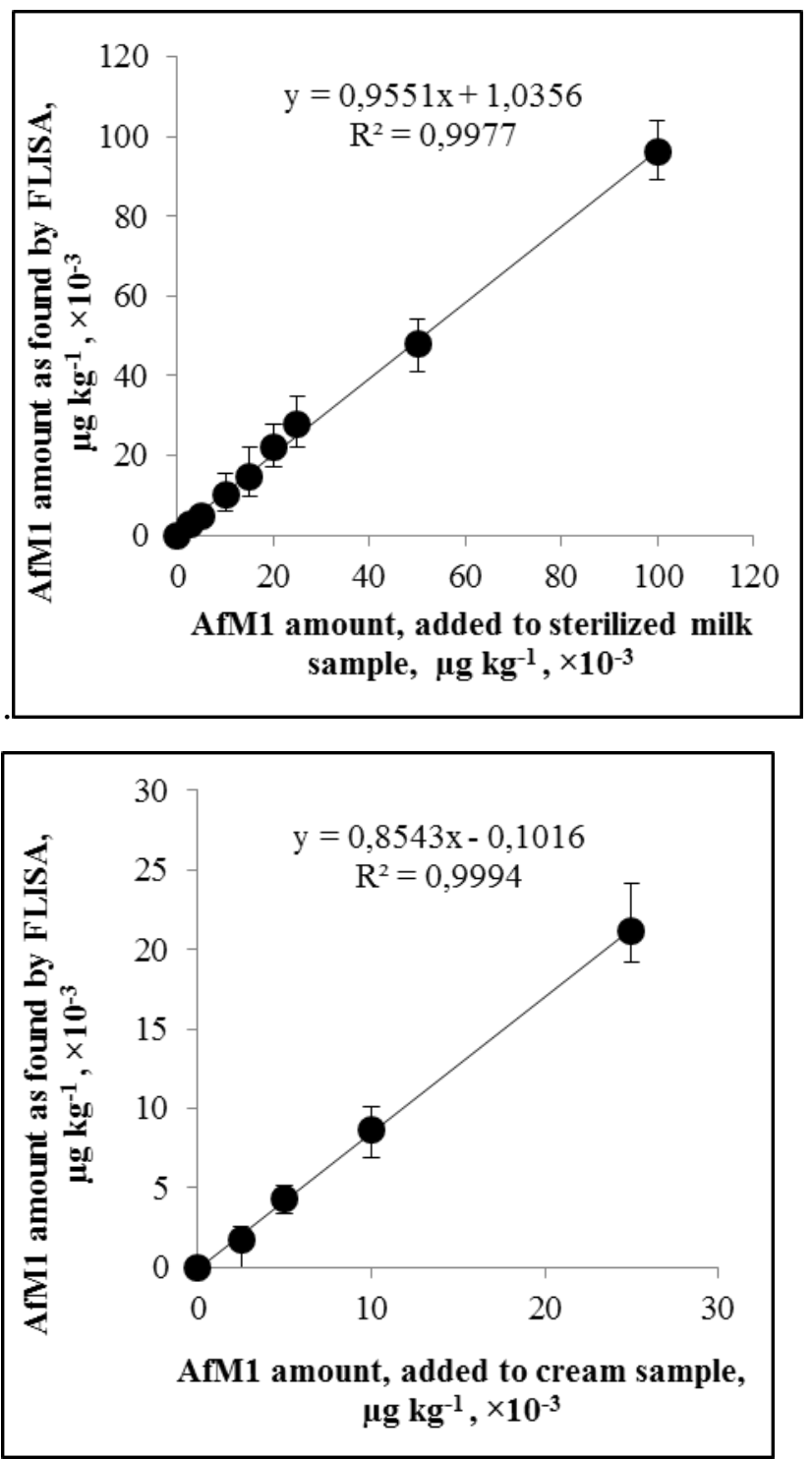

Fig. 3 Linear regression equation derived using FLISA data for aflatoxin M1 screening in artificially spiked sterilized milk (A) and cream (B) samples (data indicate averages of fivefold determinations)

B.

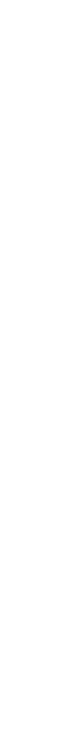$$
\text { 列 }
$$ 


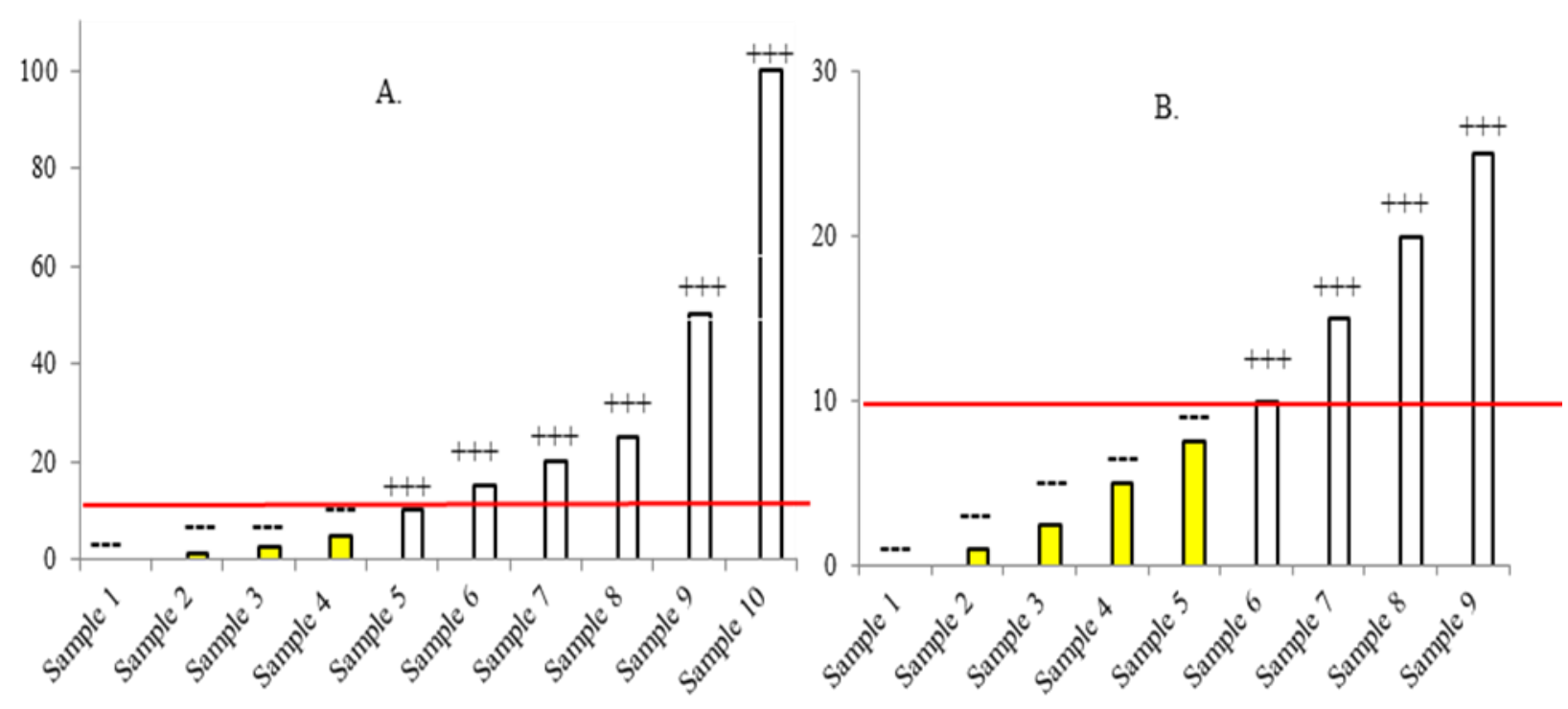

Fig. 4 Aflatoxin M1 determination in artificially spiked sterilized milk (A) and cream (B) samples by immunochemical on-site column tests $(n=3)$. Results presented as:

(yellow) or "_" - luminescence presence of the detection immunolayer,

Aflatoxin M1 concentration < cut-off level, negative result;

(white) or "+" - luminescence absence of the detection immunolayer,

Aflatoxin M1 concentration $\geq$ cut-off level, positive result 